\title{
Effect of Cutting Parameters on the Hole Quality in Dry Drilling of Some Thermoplastic Polymers
}

\begin{abstract}
FLORIN SUSAC, VALENTIN TABACARU, VIRGIL GABRIEL TEODOR, NICUSOR BAROIU*
Dunarea de J os University of Galati, Center of Excellence Polymer Processing, 47 Domneasca, 800008, Galati, Romaia

Drilling of polymeric materials can be challenging when holes are produced in large scale due to the necessity of controlling the holes quality. This paper presents the effect of machining parameters on the hole quality, in terms of surface roughness and circularity error, in drilling of high density polyethylene, polyamide and polyacetale. The analysis of variance was performed in order to assess the significance of cutting parameter on the hole quality parameters. The experimental results indicate that different cutting conditions are to be employed in order to achieve the optimum surface roughness and circularity.
\end{abstract}

Keywords: drilling, polymer, cutting parameters, ANOVA, roughness and circularity error

The continuous development of manufacturing technologies of parts with applications in aerospace and automotive industries challenges researchers to focus on materials with good mechanical properties that make them fit to their functional goal. Most often, their efforts are directed to polymers and polymer-based composite, which can successfully replace metallic or metal-composite materials in manufacturing parts for aerospace and automotive industries, depending on the demands they have to deal during parts functioning.

Although most of the polymer and polymer-based composite parts are manufactured in final shape, some machining operations such as drilling, are still needed, especially those requiring riveting and fastening. Riveting is the most common way of assembling parts in aerospace industry and this process can be challenging especially when holes are produced in large scale. It is estimated that $60 \%$ of all partrejections is due to poor hole quality [1] Hole quality is generally estimated based on a number of parameters, such as surface roughness, circularity error [2-5], which in turn are affected by the machining parameters, including drill geometry. Thus, many studies have been conducted for the last several decades to characterize the influence of cutting parameters on the hole surface quality and to understand the tool wear mechanisms in the drilling of polymers and polymer based composites [6-14]. Delamination is another major problem associated with machining of fiber-reinforced composites, which tends to reduce structural integrity of the composite structures [3-4]. Delamination can affect the assembly quality and, in particular, the tolerance in subsequence operations to drilling as riveting. Thus, different approaches including both experimental and numerical methods have been employed by researchers in order to understand the damages during machining and particularly hole making $[3,6,15-16]$. Drill geometry and material also have an important effect on the hole quality [3, 15-17]. Moreover, depending on the workpiece material structures, the delamination was analized both at the entrance as well as at the exit of the drilled hole, in the form of peel-up and push-out delamination, respectively $[3,5,16]$.

Regardless of the material type, unfilled polymers, glass fiber reinforced polymers or carbon fiber reinforced polymers, several modern technologies, such as digital microscop and ultrasonic C-scan techniques [17], light optical microscopy [16], scanning electron microscopy [7] or X-ray photoelectron spectroscopy (XPS) [9], non- distructive methods [16] were also considered in the attempt to study the influence of parameters on the quality of the machined surfaces in dry drilling, leading to an improvement of machining process quality. In order to asses the effect of various process parameters on the machinability of polymers and polymer-based composites (thrust force, torque, surface finish, circularity of the hole, delamination factor etc.), and to determine the optimal process parameters, statistical methods were considerd, such as ANOVA Taguchi design of experiments [2, 11, $12,18]$.

The aim of this study is to analyze the effect of process variables on hole quality (i.e. surface roughness, circularity and diametral errors) in dry drilling polyamide (PA6), polyacetal (POMC) and high density polyethylene (HDPE1000). Despite the fact that these polymeric materials are available at a very low price and have very good mechanical characteristics, such as strength, hardness or wear resistance, their machinability in terms of hole quality was not systematically addressed.

\section{Experimental part}

Material for workpiece and drill geometry

In this work, three polymeric materials are used as workpiece materials: high density polyethylene (grade HDPE 1000 with peek melt temperature of $135 \mathrm{C}$, Brinell hardness of 36, Young modulus of $750 \mathrm{MPa}$ ), polyamide (grade PA6 with peek melt temperature of 220C, Brinell hardness of 150, Young modulus of $3250 \mathrm{MPa}$ ) and polyacetale (grade POM-C with peek melt temperature of $165 \mathrm{C}$, Brinell hardness of 140 , Young modulus of $3100 \mathrm{MPa}$ ).

The dimensions of the workpiece are $30 \mathrm{~mm} \times 60 \mathrm{~mm} \times$ $150 \mathrm{~mm}$ (fig. 1). Two drills with diameter of 8 and $10 \mathrm{~mm}$ and point angle of $120^{\circ}$ are utilized for the drilling process (fig. 1). The drill bit substrate/material is HSS Co, a commonly industrial used high-speed steel material, also known as Cobalt steel without coating.

\section{Experimental set-up and drilling parameters}

Drilling experiments were carried out on a 2.5 axis CNC milling machine (Model EMCO MILL 55 CNC, EMCO MAIER Ges. m.b.H. Austria) that was programmed using the SINUMERIK 840D code from SIEMENS. The workpiece with a thickness of $30 \mathrm{~mm}$ was fixed on the drilling fixturing device and mounted on the machine table. Figure 1 also shows the schematic representation of the drilling set-up, including the distribution of the drilled holes. 


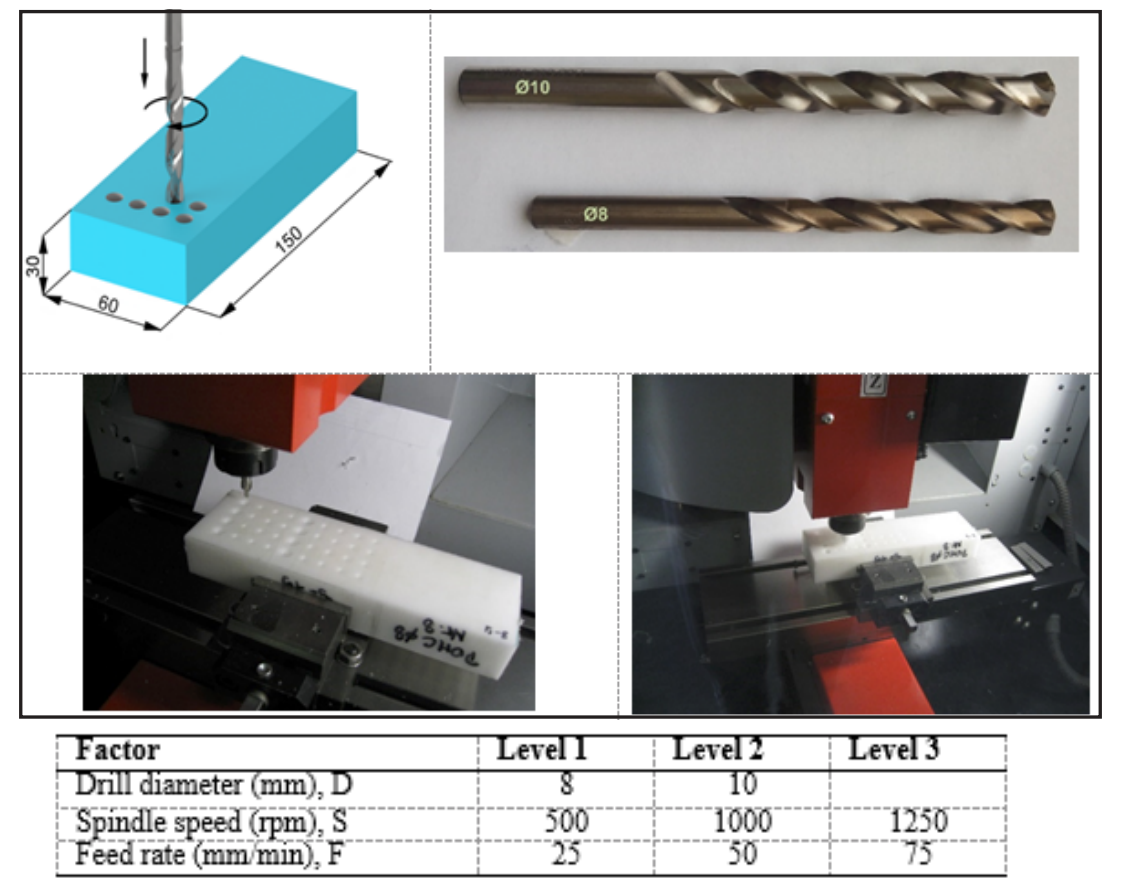

\begin{tabular}{|c|c|c|c|}
\hline DOE & Drill diameter (mm) & $\begin{array}{c}\text { Spindle speed } \\
\text { (rev/min) }\end{array}$ & $\begin{array}{c}\text { Feed rate } \\
(\mathbf{m m} / \mathrm{min})\end{array}$ \\
\hline 1 & 8 & 500 & 25 \\
\hline 2 & 8 & 500 & 50 \\
\hline 4 & 8 & 500 & 75 \\
\hline 5 & 8 & 1000 & 25 \\
\hline 6 & 8 & 1000 & 50 \\
\hline 7 & 8 & 1000 & 75 \\
\hline 8 & 8 & 1250 & 25 \\
\hline 9 & 8 & 1250 & 50 \\
\hline 10 & 8 & 1250 & 75 \\
\hline 11 & 10 & 500 & 25 \\
\hline 12 & 10 & 500 & 50 \\
\hline 13 & 10 & 500 & 75 \\
\hline 15 & 10 & 1000 & 25 \\
\hline 16 & 10 & 1000 & 50 \\
\hline 17 & 10 & 1000 & 75 \\
\hline 18 & 10 & 1250 & 25 \\
\hline & 10 & 1250 & 50 \\
\hline
\end{tabular}

Fig. 1. Experimental set-up for drilling experiments

Table 1

CUTTING PARAMETERS USED IN

THE DRILLING EXPERIMENTS
Table 2

DRILLING EXPERIMENTAL PLAN
The drilling experiments conducted in this work combined spindle speed, feed rate, and drill diameters. The experimental plan consists of a full factorial design with two factors at three levels (spindle speed and feed rate) and one factor at two levels (drill diameter), as shown in table 1. The drilling experiments were carried out randomly but, for comparison purpose, the same order was applied for all three investigated materials. In order to investigate the repeatability and reproducibility, each combination of experimental parameters in table 2 was repeated four times.

For each experimental line in table 2, the temperature of the drill, after drilling of the fourth hole, was monitored/ measured using a thermal image camera (Flir i7, FLIR SYSTEMS Inc. USA) to ensure that the drilled holes experience the same thermo-mechanical history. Before a new experimental line started, the drill was allowed to cool down until the room temperature $\left(23 \pm 1^{\circ} \mathrm{C}\right)$. Moreover, for each material, when the set of four holes was completed, the drill was inspected on optical microscope for wear and no significant tool wear was observed. Thus, the same drill was used for machining all three materials.
Surface roughness measurement

A profilometer (Mitutoyo Surftest SJ -210, Japan) equipped with Surftest SJ Communication Tool software was used for measuring the $R$ surface roughness. Details of experimental set-up used for the measurement of roughness parameter $R_{a}$ of drilled holes are presented in figure 2 .

\section{Diameter and circularity error measurement}

The coordinate measuring machine (MH3D, Tesa, Switzerland) was used for diameter and circularity error measurements. Figure 3 shows the experimental set-up for circularity error measurement and schematically presents the measurement procedure. For each drilled hole, the error was measured in 8 points at about $1 \mathrm{~mm}$ below the hole entry side, and the average measurement values are considered for the statistical analysis.

The circularity error at the hole entry was defined as the difference between the maximum radius $\left(D_{\min }\right)$ of a circle that can be circumscribed outside the circular hole profile and the maximum radius $\left(D_{0}\right)$ of a circle that can be 


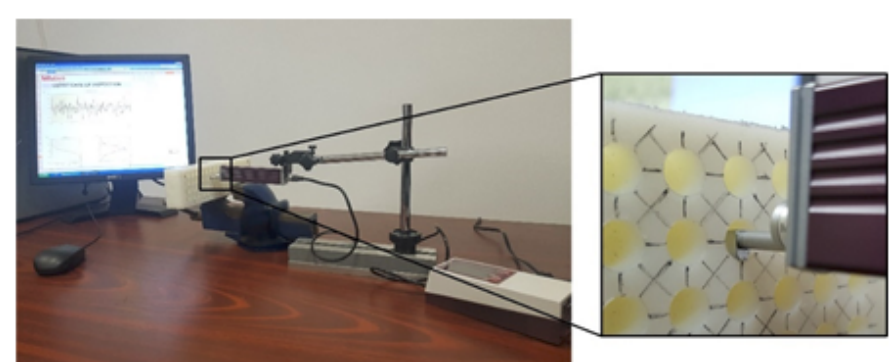

Fig. 2. Measurement set-up for surface roughness
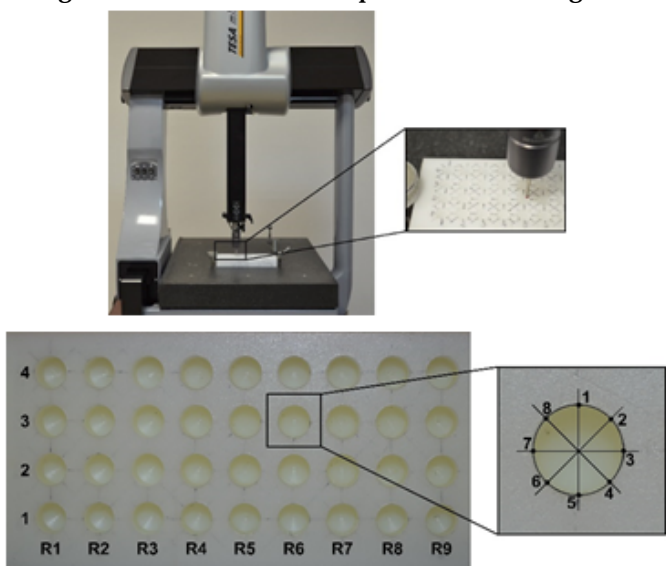

Fig. 3. Experimental set-up for circularity error measurement inscribed and completely enclose the circular hole profile without cutting it and is concentric with the maximum circumscribed circle [7], as shown in figure 4.

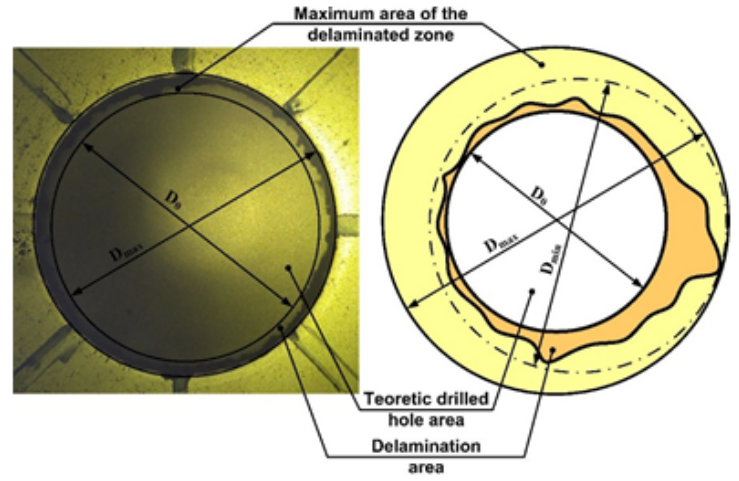

Fig. 4. Schematic representation of circularity error determination

The maximum area of the delaminated zone is given by the maximum radius $\left(D_{\text {max }}\right)$ from the delaminated zone which is the distance between the center of theoretical hole and the furthest point belonging to the delaminated zone. The theoretic drilled hole is the programmed diameter of the machined hole $\left(D_{0}\right)$.

\section{Statistical analysis}

For each of the three investigated polymers, the analysis of variance (ANOVA) was used to assess the statistical significance of a given parameter or a combination of parameters on the response parameters $\left(R_{a}\right.$, hole circularity error) [19]. The P-values less than 0.05 in ANOVA tables means that the effect of the factors (spindle speed, feed rate, and drill diameter) and their interactions on the response parameters are significant at $95 \%$ confidence level. Main effects plots were also constructed to further support the findings from the ANOVA. It should be noted that priori to ANOVA the Anderson-Darling normality test was applied to check the normality hypothesis [19].

\section{Results and discussions}

\section{Circularityerror}

Figure 5 shows the variation of the average hole circularity as a function of the process parameters (average and standard deviation of four drilled holes). A circularity error value of 0 indicates a perfect circle, i.e. the measured hole diameter is equal to the drill bit diameter. The average nominal hole diameter in HDPE was observed to be very close to the drill bit diameter, the maximum relative error between the drill diameter and nominal hole diameter was $1 \%$. For HDPE, the circularity error was observed to varies between $0.0125 \pm 0.004 \mathrm{~mm}$ for DOE12 (table 2) to $0.0398 \pm 0.034 \mathrm{~mm}$ for DOE6 when drilling at a feed rate of $75 \mathrm{~mm} / \mathrm{min}$ and a spindle speed of 1000 with a drill diameter of $10 \mathrm{~mm}$. In particular, drilling HDPE with a spindle speed of $500 \mathrm{rpm}$ and drill diameter of $10 \mathrm{~mm}$ yields the best results with regard to the hole diameter, i.e. the relative error less than $0.03 \%$.

For PA6, the circularity error was observed to varies between $0.0193 \pm 0.009 \mathrm{~mm}$ for DOE3 to $0.1365 \pm 0.097$ $\mathrm{mm}$ for DOE7 (fig. 5b). However, overall, it is observed that the circularity error increased with the increase of
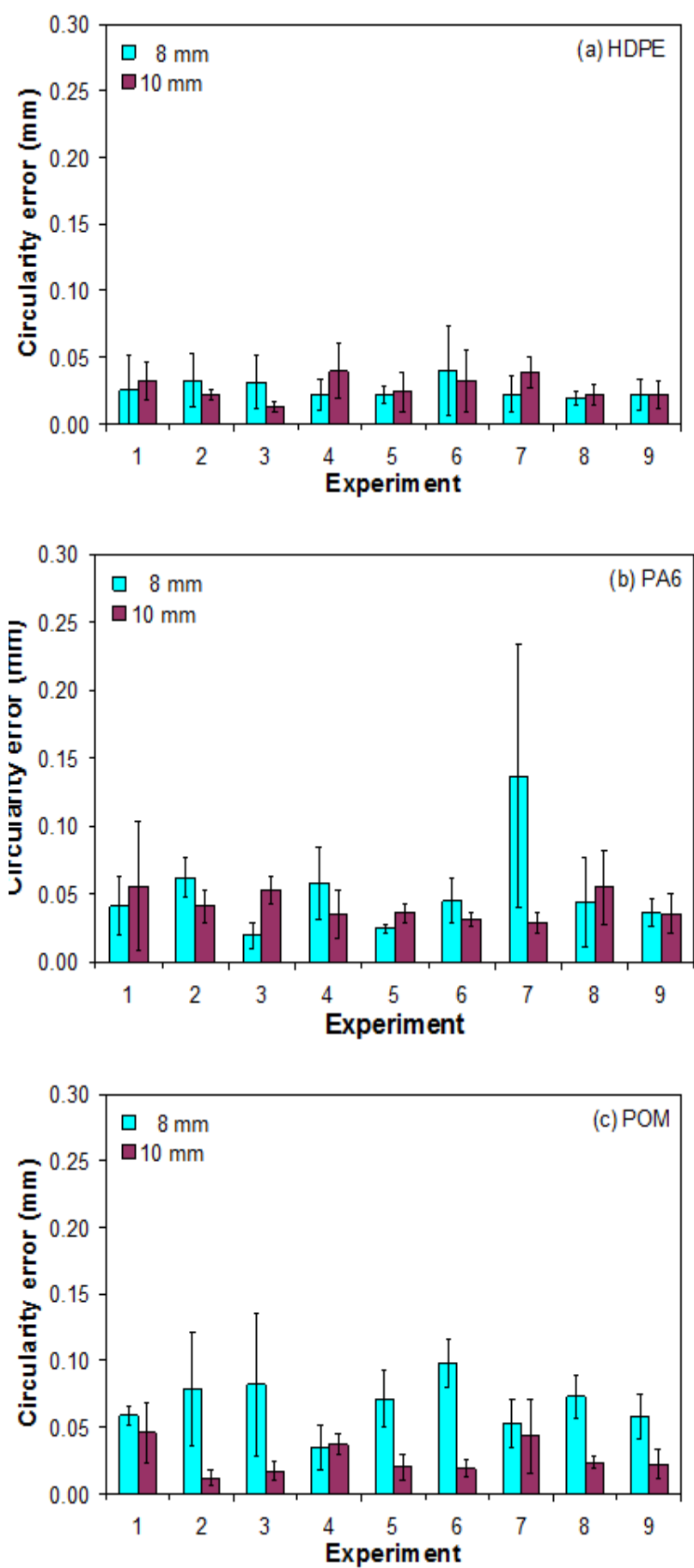

Fig. 5. Variation of the average hole circularity 

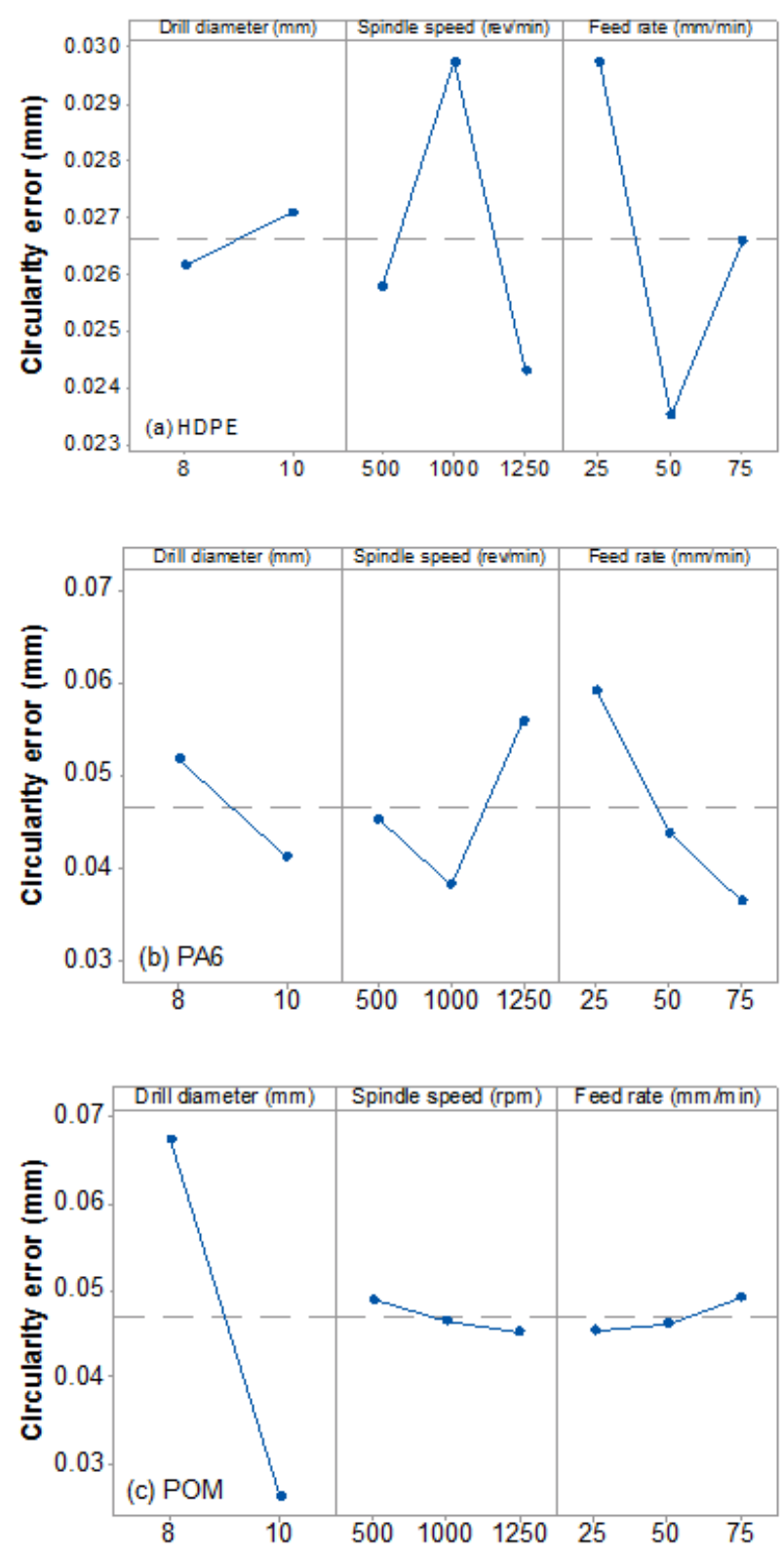

Fig. 6. Main effect plots for hole circularity spindle speed due to the increase of vibrations that causes instability of the cutting tool, and decreases with the increase of drill diameter and feed rate. At higher spindle speeds and low er feed rates the cutting tool rubs around the hole wall more frequently causing higher distortions which increase the circularity error.

For POM, as shown in figure $5 c$, the circularity error significantly decreased with increasing drill diameter for the same cutting parameters. For example, when drilling at a feed rate/spindle speed ratio of $0.1(\mathrm{~mm} / \mathrm{min}$ ) $/ \mathrm{rev}$ (i.e. $50 / 500$ ), circularity error decreases from $0.0787 \pm 0.043$ $\mathrm{mm}$ to $0.0117 \pm 0.006 \mathrm{~mm}$ with increasing drill diameter from 8 to $10 \mathrm{~mm}$. Similar trends were also observed for the other feed rate/spindle speed ratios.

Comparing the hole circularity results obtained for HDPE, PA6 and POM, it can be concluded that the HDPE presents the best hole circularity followed by PA6 and POM.

Since improvement in hole circularity was not always consistently observed, the ANOVA analysis was applied to determine the effect of process parameters on the circularity.

Table 3 presents the ANOVA results for circularity error when drilling holes in HDPE, while figure 6a shows the main effects plot for the average hole circularity. It could be observed that the spindle speed $(S)$ and feed rate $(F)$ and the two-way interactions between drill diameter and spindle speed, drill diameter and feed rate and spindle speed and feed rate have a significant effect on the circularity (P-value $<\alpha)$ with a contribution of $9.40 \%$, $11.54 \%, 17.13 \%, 38.55 \%$ and $21.69 \%$, respectively.

The analysis of the ANOVA results given in table 4 shows that, within the experimental window adopted in this study, the circularity of the drilled holes in PA6 is not significantly affected by any of the cutting parameters ( $P$-value $>\alpha$ ). However, the feed rate has a contribution of $8.53 \%$, while the two-way interaction between drill diameter and spindle speed, drill diameter and feed rate, and spindle speed and feed rate have some impact on the circularity with a contribution of $14.47 \%, 11.93 \%$ and $16.40 \%$, respectively. For PA6, the optimum combination for obtaining the lowest circularity error is drill diameter $10 \mathrm{~mm}$, spindle speed 1000 $\mathrm{rev} / \mathrm{min}$, and feed rate $75 \mathrm{~mm} / \mathrm{min}$.

Table 3

ANOVA FOR CIRCULARITY ERROR (mm) FOR HDPE

\begin{tabular}{|c|c|c|c|c|c|c|}
\hline Source & DF & Seq SS & Adj SS & Adj MS & $\mathbf{F}$ & $\mathbf{P}$ \\
\hline Drill diameter (mm) & 1 & 0.000004 & 0.000004 & 0.000004 & 1.21 & 0.332 \\
\hline Spindle speed (rev/min) & 2 & $9.54 \mathrm{E}-05$ & $9.54 \mathrm{E}-05$ & $4.77 \mathrm{E}-05$ & 14.43 & 0.015 \\
\hline Feed rate $(\mathrm{mm} / \mathrm{min})$ & 2 & 0.000117 & 0.000117 & $5.86 \mathrm{E}-05$ & 17.73 & 0.010 \\
\hline Drill diameter $(\mathrm{mm}) \times$ Spindle speed $(\mathrm{rev} / \mathrm{min})$ & 2 & 0.000174 & 0.000174 & $8.69 \mathrm{E}-05$ & 26.3 & 0.005 \\
\hline Drill diameter $(\mathrm{mm}) \times$ Feed rate $(\mathrm{mm} / \mathrm{min})$ & 2 & 0.000391 & 0.000391 & 0.000196 & 59.21 & 0.001 \\
\hline Spindle speed $(\mathrm{rev} / \mathrm{min}) \times$ Feed rate $(\mathrm{mm} / \mathrm{min})$ & 4 & 0.00022 & 0.00022 & $5.51 \mathrm{E}-05$ & 16.66 & 0.009 \\
\hline Residual Error & 4 & $1.32 \mathrm{E}-05$ & $1.32 \mathrm{E}-05$ & $3.3 \mathrm{E}-06$ & & \\
\hline Total & 17 & 0.001015 & & & & \\
\hline
\end{tabular}

Table 4

ANOVA FOR CIRCULARITY ERROR (mm) FOR PA6

\begin{tabular}{|c|c|c|c|c|c|c|}
\hline Source & DF & Seq SS & Adj SS & Adj MS & $\mathbf{F}$ & $\mathbf{P}$ \\
\hline Drill diameter (mm) & 1 & 0.000501 & 0.000501 & 0.000501 & 0.56 & 0.497 \\
\hline Spindle speed (rev/min) & 2 & 0.000939 & 0.000939 & 0.00047 & 0.52 & 0.629 \\
\hline Feed rate $(\mathrm{mm} / \mathrm{min})$ & 2 & 0.001593 & 0.001593 & 0.000796 & 0.88 & 0.481 \\
\hline Drill diameter $(\mathrm{mm}) \times$ Spindle speed $(\mathrm{rev} / \mathrm{min})$ & 2 & 0.001313 & 0.001313 & 0.000657 & 0.73 & 0.537 \\
\hline Drill diameter $(\mathrm{mm}) \times$ Feed rate $(\mathrm{mm} / \mathrm{min})$ & 2 & 0.001805 & 0.001805 & 0.000903 & 1 & 0.444 \\
\hline Spindle speed $(\mathrm{rev} / \mathrm{min}) \times$ Feed rate $(\mathrm{mm} / \mathrm{min})$ & 4 & 0.001248 & 0.001248 & 0.000312 & 0.35 & 0.836 \\
\hline Residual Error & 4 & 0.003606 & 0.003606 & 0.000901 & & \\
\hline Total & 17 & 0.011005 & & & & \\
\hline
\end{tabular}


Table 5

ANOVA FOR CIRCULARITY ERROR $(\mathrm{mm})$ FOR POM

\begin{tabular}{|l|r|r|r|r|r|r|}
\hline Source & DF & Seq SS & Adj SS & Adj MS & F & P \\
\hline Drill diameter $(\mathrm{mm})$ & $\mathbf{1}$ & $\mathbf{0 . 0 0 7 5 5 1}$ & $\mathbf{0 . 0 0 7 5 5 1}$ & $\mathbf{0 . 0 0 7 5 5 1}$ & $\mathbf{6 9 . 9 1}$ & $\mathbf{0 . 0 0 1}$ \\
\hline Spindle speed (rev/min) & 2 & $4.29 \mathrm{E}-05$ & $4.29 \mathrm{E}-05$ & $2.15 \mathrm{E}-05$ & 0.2 & 0.827 \\
\hline Feed rate $(\mathrm{mm} / \mathrm{min})$ & 2 & $4.88 \mathrm{E}-05$ & $4.88 \mathrm{E}-05$ & $2.44 \mathrm{E}-05$ & 0.23 & 0.807 \\
\hline Drill diameter $(\mathrm{mm}) \times$ Spindle speed (rev/min) & 2 & 0.000213 & 0.000213 & 0.000107 & 0.99 & 0.449 \\
\hline Drill diameter (mm) $\times$ Feed rate (mm/min) & $\mathbf{2}$ & $\mathbf{0 . 0 0 2 6 2 3}$ & $\mathbf{0 . 0 0 2 6 2 3}$ & $\mathbf{0 . 0 0 1 3 1 2}$ & $\mathbf{1 2 . 1 4}$ & $\mathbf{0 . 0 2 0}$ \\
\hline Spindle speed (rev/min) $\times$ Feed rate(mm/min) & 4 & 0.00059 & 0.00059 & 0.000148 & 1.37 & 0.385 \\
\hline Residual Error & 4 & 0.000432 & 0.000432 & 0.000108 & & \\
\hline Total & $\mathbf{1 7}$ & $\mathbf{0 . 0 1 1 5 0 1}$ & & & & \\
\hline
\end{tabular}

The ANOVA results reported in table 5 shows that, when drilling POM, the drill diameter and interaction between drill diameter and feed rate has significant impact on the circularity error, contributing by $65.66 \%$ and $22.81 \%$, respectively. For POM, the optimum combination for obtaining the lowest circularity error is drill diameter 10 $\mathrm{mm}$, spindle speed $1250 \mathrm{rev} / \mathrm{min}$, and feed rate $25 \mathrm{~mm} /$ $\mathrm{min}$. How ever, the spindle speed and feed rate as well as other interactions were not significant and their contribution did not exceed $5 \%$.
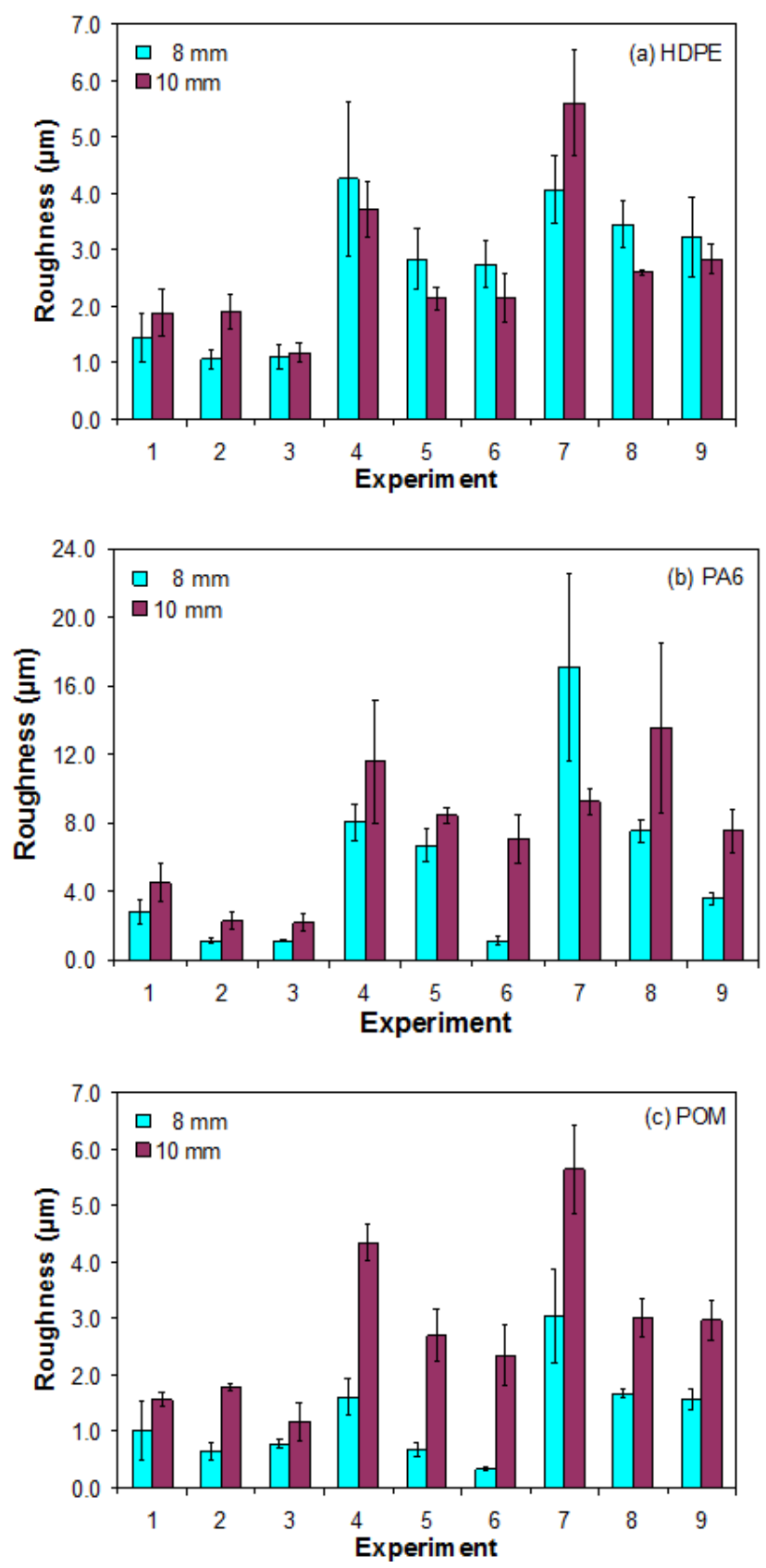

Fig. 7. Average arithmetic surface roughness Ra
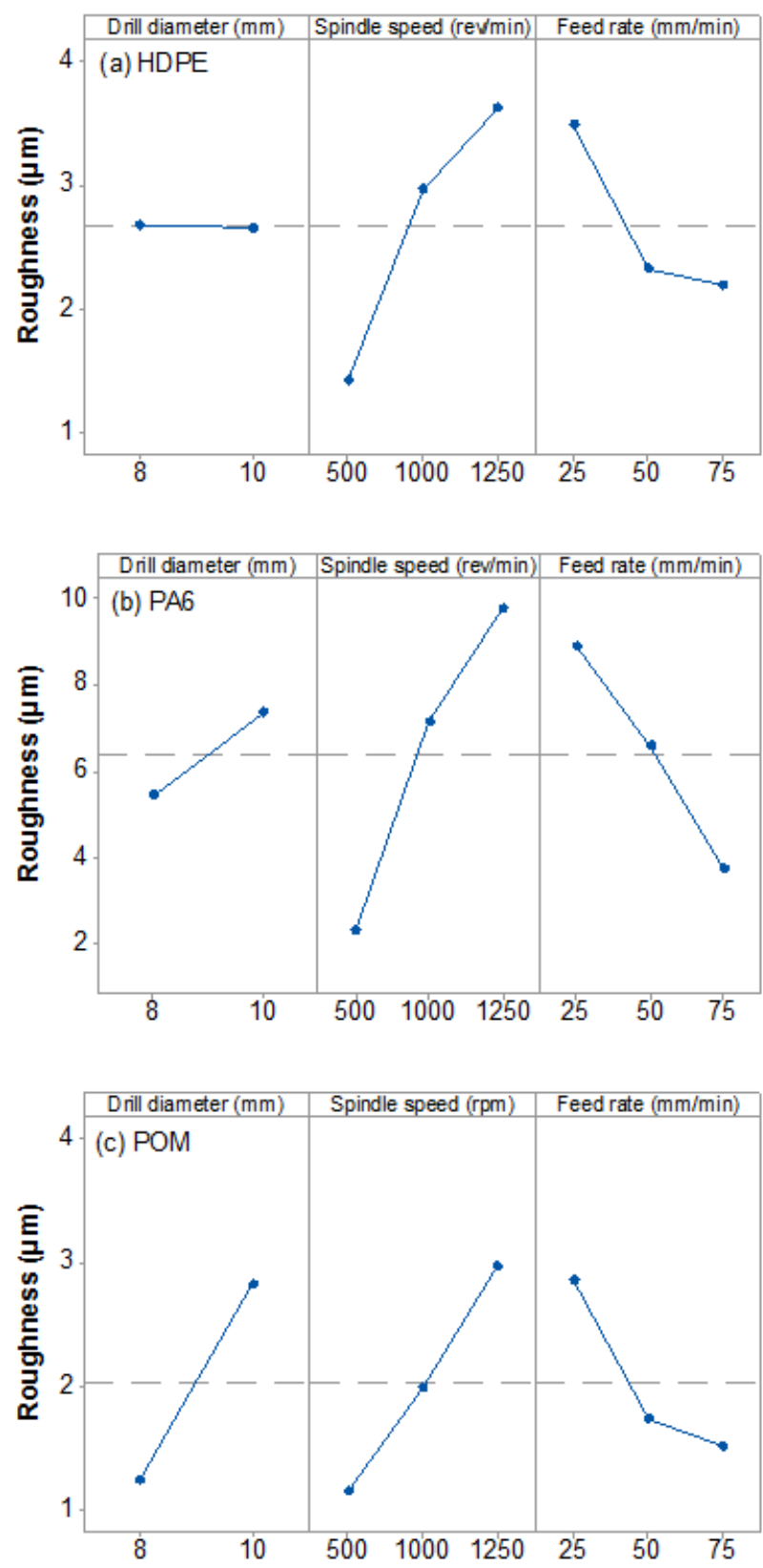

Fig. 8. Main effects plot for surface roughness

Improvement in circularity was not always consistently observed. However, from the present study, a feed rate of $75 \mathrm{~mm} / \mathrm{min}$ yielded a favorable result in terms of circularity error and hole diameter regardless of the spindle speed and drill diameter.

Surface roughness analysis

Figure 7 shows the average values for $R_{a}$ (average surface roughness) of drilled holes under different cutting parameters for the three polymers considered in the study. 
For HDPE, the $R_{\text {a }}$ ranged between 1.06 and $5.61 \mu \mathrm{m}$ (fig. $7 a)$. The highest $R$ value was found when drilling with higher spindle speed and lower feed rate. In the case of PA6 (fig. 7b), the surface roughness was found to vary between 1.10 and $17.125 \mu \mathrm{m}$. The highest surface roughness was observed at higher spindle speed (1250 $\mathrm{rpm})$, lower feed rate $(25 \mathrm{~mm} / \mathrm{rev})$ and lower drill diameter $(8 \mathrm{~mm})$. Drilling of POM plates with different cutting tool diameters and within the experimental window adopted in this study led to a range of surface roughness values between 0.318 and $5.64 \mu \mathrm{m}$, as can be seen in figure 7c.

Overall, it was observed that when drilling with the 10 $\mathrm{mm}$ drill diameter, $R$ increased regardless of the spindle speed and feed rate (fig. 8). The highest surface roughness was obtained when drilling with high cutting spindle speed (1250 rpm), low rate $(25 \mathrm{~mm} / \mathrm{min})$, as shown in figure 8 .

The ANOVA results reported in table 6 shows that, when drilling HDPE, the spindle speed and feed rate have significant impact on $R_{a^{\prime}}$ contributing by $59.64 \%$ and 23.63\%respectively, while the drill diameter did not have any significant contribution. The drill diameter and the linear interactions between the input parameters were less significant and did not exceed 10\% (table 6).

Based on the ANOVA table 7, it is the sole spindle speed that significantly affect the surface roughness of the drilled holes in PA6 ( $P$-value $<0.05)$, contributing by $48.13 \%$, followed by the feed rate (22.30\%), and drill diameter (4.66\%). However, the effect of drill diameter, feed rate and interaction between drill diameter and spindle speed and feed rate are not statistically significant ( $P$-value $>0.05$ )

For POM, the drill diameter, spindle speed and feed rate have a significant effect on the $R_{a^{\prime}}$ contributing $34.41 \%$, $30.41 \%$ and $19.08 \%$, respectively, as shown by ANOVA results in table 8 . In addition, interaction between drill diameter and spindle speed has a significant effect on the $R_{a^{\prime}}$ with a contribution of $5.95 \%$ (table 8 ).

The analysis of variance for the $R_{a}$ leads to the conclusion that, in the range investigated, the optimum combination of the cutting parameters that generates the lowest roughness is given by the lower spindle speed and higher feed rate, regardless of the drilled materials.

Table 6

ANOVA FOR SURFACE ROUGHNESS FOR HDPE

\begin{tabular}{|c|c|c|c|c|c|c|}
\hline Source & DF & Seq SS & Adj SS & Adj MS & $\mathbf{F}$ & $\mathbf{P}$ \\
\hline Drill diameter $(\mathrm{mm})$ & 1 & 0.0021 & 0.0021 & 0.00209 & 0.01 & 0.938 \\
\hline Spindle speed (rev/min) & 2 & 15.3334 & 15.3334 & 7.6667 & 25.28 & 0.005 \\
\hline Feed rate $(\mathrm{mm} / \mathrm{min})$ & 2 & 6.0749 & 6.0749 & 3.03744 & 10.02 & 0.028 \\
\hline Drill diameter $(\mathrm{mm}) \times$ Spindle speed $(\mathrm{rev} / \mathrm{min})$ & 2 & 0.8874 & 0.8874 & 0.4437 & 1.46 & 0.334 \\
\hline Drill diameter $(\mathrm{mm}) \times$ Feed rate $(\mathrm{mm} / \mathrm{min})$ & 2 & 0.5636 & 0.5636 & 0.28178 & 0.93 & 0.466 \\
\hline Spindle speed $(\mathrm{rev} / \mathrm{min}) \times$ Feed rate $(\mathrm{mm} / \mathrm{min})$ & 4 & 1.637 & 1.637 & 0.40926 & 1.35 & 0.389 \\
\hline Residual Error & 4 & 1.2131 & 1.2131 & 0.30326 & & \\
\hline Total & 17 & 25.7114 & & & & \\
\hline
\end{tabular}

Table 7

ANOVA FOR SURFACE ROUGHNESS FOR PA6

\begin{tabular}{|l|r|r|r|r|r|r|}
\hline Source & DF & Seq SS & Adj SS & Adj MS & F & P \\
\hline Drill diameter $(\mathrm{mm})$ & 1 & 16.513 & 16.513 & 16.513 & 1.54 & 0.282 \\
\hline Spindle speed $(\mathrm{rev} / \mathrm{min})$ & 2 & 170.515 & 170.515 & 85.258 & 7.97 & 0.04 \\
\hline Feed rate $(\mathrm{mm} / \mathrm{min})$ & 2 & 79.019 & 79.019 & 39.51 & 3.69 & 0.123 \\
\hline Drill diameter $(\mathrm{mm}) \times$ Spindle speed $(\mathrm{rev} / \mathrm{min})$ & 2 & 7.828 & 7.828 & 3.914 & 0.37 & 0.715 \\
\hline Drill diameter $(\mathrm{mm}) \times$ Feed rate $(\mathrm{mm} / \mathrm{min})$ & 2 & 17.966 & 17.966 & 8.983 & 0.84 & 0.496 \\
\hline Spindle speed $(\mathrm{rev} / \mathrm{min}) \times$ Feed rate $(\mathrm{mm} / \mathrm{min})$ & 4 & 19.647 & 19.647 & 4.912 & 0.46 & 0.765 \\
\hline Residual Error & 4 & 42.781 & 42.781 & 10.695 & & \\
\hline Total & 17 & 354.269 & & & & \\
\hline
\end{tabular}

Table 8

ANOVA FOR SURFACE ROUGHNESS FOR POM

\begin{tabular}{|l|r|r|r|r|r|r|}
\hline Source & DF & Seq SS & Adj SS & Adj MS & F & P \\
\hline Drill diameter $(\mathrm{mm})$ & 1 & 11.2396 & 11.2396 & 11.2396 & 97.17 & 0.001 \\
\hline Spindle speed $(\mathrm{rpm})$ & 2 & 10.0167 & 10.0167 & 5.0083 & 43.3 & 0.002 \\
\hline Feed rate $(\mathrm{mm} / \mathrm{min})$ & 2 & 6.2317 & 6.2317 & 3.1159 & 26.94 & 0.005 \\
\hline Drill diameter $(\mathrm{mm}) \times$ Spindle speed $(\mathrm{rmm})$ & 2 & 1.9426 & 1.9426 & 0.9713 & 8.4 & 0.037 \\
\hline Drill diameter $(\mathrm{mm}) \times$ Feedrate $(\mathrm{mm} / \mathrm{min})$ & 2 & 0.3709 & 0.3709 & 0.1854 & 1.6 & 0.308 \\
\hline Spindle speed $(\mathrm{rpm}) \times$ Feed rate $(\mathrm{mm} / \mathrm{min})$ & 4 & 2.3949 & 2.3949 & 0.5987 & 5.18 & 0.07 \\
\hline Residual Error & 4 & 0.4627 & 0.4627 & 0.1157 & & \\
\hline Total & 17 & 32.6591 & & & & \\
\hline
\end{tabular}

\section{Conclusions}

In this paper, the hole quality, i.e. hole circularity and surface roughness, was assessed in drilling of HDPE, PA6 and POM as a function of feed rate, spindle speed, and drill diameter. Based on the experimental data and statistical analysis, some key observations can be made: (i) Although improvement in circularity was not always consistently observed in all drilled polymers, in general, the circularity error decreases with increasing feed rate. Thus, from our study, it can be concluded that a feed rate of $75 \mathrm{~mm} / \mathrm{min}$ yields favorable results in terms of circularity and hole diameter. 
(ii) Surface roughness increases with increasing spindle speed and drill diameter and decreases with increasing feed rate. The optimum surface roughness is obtained when drilling with lower spindle speed (500 rev/min) and drill diameter $(8 \mathrm{~mm})$, and higher feed rate $(75 \mathrm{~mm} / \mathrm{min})$.

(iii) If the surface roughness is the machinability criterion, then the POM exhibits the best machinability followed by HDPE and PA6.

\section{References}

1. CAPELLO, E., LANGELlA, A., NELE, L., PAOLETti, A., SANTO, L., TAGLIAFERRI, V., Machining: Fundamentals and recent advances, Drilling polymeric matrix composites, Springer-Verlag London Limited, J. Paulo Davin, Aveiro, 2008, p. 172

2. DOMINGO R., MARIN, M., DE AUGUSTINA, B., CALVO, R., Procedia Eng., 132, 2015, p. 448

3. GRILO, T. J., PAULO, R. M. F., SILVA, C. R. M., DAVIM, J .P., Composites Part B, 45, 2013, p. 1344

4. HEIDARY, H., KARIMI, N. Z., MINAK, G., Compos. Struct., 201, 2018, p. 112

5. KAVAD, B. V., PANDEY, A. B., TADAVI, M. V., J AKHARIA, H. C., Procedia Technology, , 2014, p. 457

6. WANG14, G. D., MELLY, S. K., LI, N., PENG, T., LI, Y., Compos. Struct., 200, 2018, p. 679

7. GIASIN, K., GOREY, G., BYRNE, C., SINKE, J., BROUSSEAU, E., Compos. Struct., 212, 2019, p. 159
8. CANTARAGIU, A. M., FeteCAU, C., PARASCHIV, G., Mat. Plast., 52, no. 1,2015

9. MUNTEANU, A. V., FETECAU, C., STAN, F., LUNGU, A., IOVU, H., Mat. Plast., 46, no. 2, 2009

10. VLAD, D., FETECAU., C., DOICIN, C., PALADE, L. I., Mat. Plast., 50, no. 4, 2013

11. VASILE, G., FETECAU, C., SERBAN, A., Mat. Plast., 51, no. 2, 2014

12. VASILE, G., FETECAU, C., AMARANDEl, D., SERBAN, A., Mat. Plast., 53, no. 1, 2016

13. FETECAU, C., STAN, F., MUNTEANU A., POPA, V., Int. J. Mater. Form., 1, Suppl 1, 2008, p. 515

14. STAN, F., VLAD, D., FETECAU, C., ASME International Manufacturing Science and Engineering Conference, 2013, p. V001T01A022;

15. PARK, S. Y., CHOI, W. J., CHOI, C. H., CHOI, S. H., Compos. Struct., 185, 2018, p. 684

16. HRECHUK, A., BUSHLYA, V., STAHL, J. E., Compos. Struct., 204, 2018, p. 378

17. XU, J., LI, C., MI, S., AN, Q., CHEN M, Compos. Struct., 201, 2018, p. 1076

18. VANKANTI, V. K., GANTA, V., J. Mater. Res. Technol., 3, nr. 1, 2014, p. 35

19. MONGOMERY, D. C., Design and analysis of experiments, $7^{\text {th }}$ Edition, John Wiley \& Sons, 2009.

Manuscript received: 18.12 .2018 